\title{
Local ecological knowledge as a tool for assessing the status of threatened vertebrates: a case study in Vietnam
}

\author{
Luis Santiago Cano and José Luis Tellería
}

\begin{abstract}
This study draws on the local ecological knowledge of 58 hunters from seven communes in the Ngoc Son Ngo Luong Nature Reserve (Hoa Binh province, North Vietnam) to examine the local status of 40 threatened vertebrates. The reserve forms part of a biodiversity-rich mountainous corridor. Respondents were shown photographs of the species and asked to rate their abundance on a scale of $0-3$ (o, extinct; 3 , very abundant) in two periods: pre-1975 (before Doi Moi) and in 2009. The results show that 39 species have lived in the area and five are now extinct (Delacour's langur Trachypithecus delacouri, northern white-cheeked crested gibbon Nomascus leucogenys, dhole Cuon alpinus, oriental small-clawed otter Aonyx cinereus, Indochinese tiger Panthera tigris corbetti) and the presence of another six is doubtful (Phayre's leaf-monkey Trachypithecus phayrei ssp. crepuscula, sun bear Helarctos malayanus, binturong Arctictis binturong, fishing cat Prionailurus viverrinus, leopard Panthera pardus, wreathed hornbill Anorrhinus undulatus). The results show a general decline in numbers and abundance, with mammals declining fastest, especially carnivores and primates. The differences in abundance between species have narrowed since 1975, converging towards trends of general impoverishment at similar low abundances. The survey results were similar among communes and also concord with the findings of research in nearby areas. This study demonstrates the usefulness of local ecological knowledge for planning, decision-making and management of protected areas in the absence of historical records or financial resources for conducting intensive fieldwork in remote and little-known areas.
\end{abstract}

Keywords Local ecological knowledge, mammal, Ngoc Son Ngo Luong Nature Reserve, threatened vertebrate, Vietnam

This paper contains supplementary material that can be found online at http://journals.cambridge.org

Luis SANTIAgo CANO (Corresponding author)* Forest Protection Department Hoa Binh, Phuong Lam Ward, Hoa Binh city, Hoa Binh province, Vietnam E-mail catuche.gallego@gmail.com

José Luis TelLería Departamento de Zoología y Antropología Física, Facultad de Ciencias Biológicas, Universidad Complutense, Madrid, Spain

*Current address: Departamento de Zoología y Antropología Física, Facultad de Ciencias Biológicas, Universidad Complutense, 28040 Madrid, Spain

Received 19 August 2011. Revision requested 5 October 2011.

Accepted 9 November 2011.

\section{Introduction}

Tocal ecological knowledge can provide information on 1 the presence, abundance, behaviour and ecology of species, and traditional ecological knowledge is the cumulative body of knowledge, practice and belief built up in the interaction of people with each other and with their environment (Berkes, 2008; Rasalato et al., 2010). Traditional ecological knowledge involves cultural transmission whereas local ecological knowledge is free of subjective cultural perceptions and has therefore been suggested as a useful and objective method for studying the status of wild animal populations in three scenarios: remote areas where there have been no appropriate scientific studies (Wilhere, 2002; Rasalato et al., 2010), areas that are suffering drastic biodiversity loss (Starr et al., 2011), and areas in which knowledge is urgently needed to implement appropriate conservation measures (Usher, 2000; Steinzmetz et al., 2006; Starr et al., 2011).

This study taps into the local ecological knowledge of hunters of the seven communes in the Ngoc Son Ngo Luong Nature Reserve in Hoa Binh province, North Vietnam, to examine the status, distribution and any trends of 40 species of threatened vertebrates in the Red Data Book of Vietnam (Ministry of Science and Technology, 2007). This Reserve lies in the centre of a karstic mountain range considered to be a key site for biodiversity conservation in Vietnam (Baltzer et al., 2001), between Cuc Phuong National Park and the Pu Luong Nature Reserve (Fig. 1). As well as an important Nature Reserve in its own right, Ngoc Son Ngo Luong acts as an ecological corridor between these two protected areas. Despite this importance little is known about the species in Ngoc Son Ngo Luong (BirdLife International \& FIPI, 2001).

In the mid 2oth century the region was an area of unspoilt woodland inhabited by rare species such as Delacour's langur Trachypithecus delacouri, the dhole Cuon alpinus, sun bear Helarctos malayanus and Indochinese tiger Panthera tigris corbetti. Since implementation of Doi Moi ('renovation', an economic reform undertaken in Vietnam in the late 1980s; Castella et al., 2006), however, forestry and mining activities have increased in the area and there has also been an increase in the human population. This research was undertaken with the Forestry Protection Department of Hoa Binh province (Bui Binh et al., 2008; Cano \& Pham, 2010) for planning the use and conservation management of the species in this protected area. 


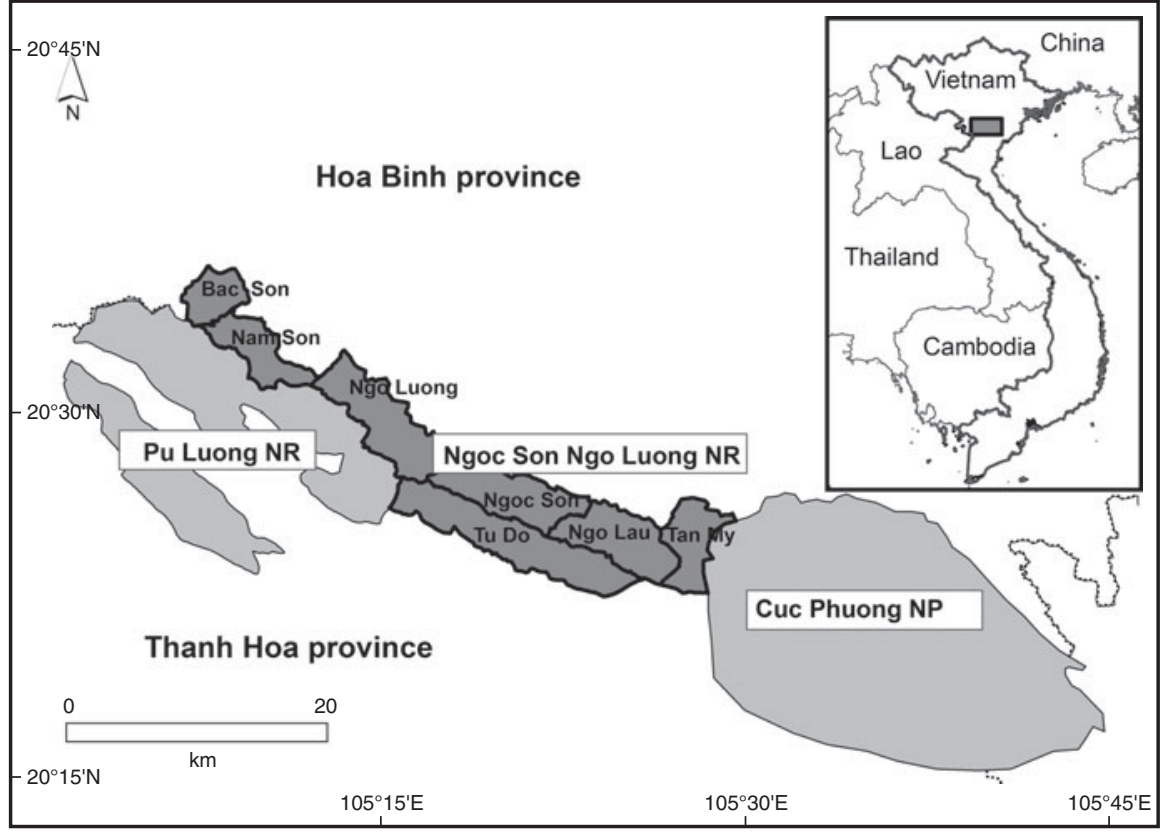

Fig. 1 Location of Ngoc Son Ngo Luong Nature Reserve, with its seven communes (Table 1), lying between Cuc Phuong National Park and Pu Luong Nature Reserve. The shaded rectangle on the inset indicates the location of the main map in northern Vietnam.
Our aims were threefold: (1) Although there was previously some information available on the biodiversity of adjacent protected areas (FFI, 2005), there was no detailed information on Ngoc Son Ngo Luong Nature Reserve. A preliminary inventory (Dat et al., 2008) found that Delacour's langur had recently disappeared and noted other conservation problems. We therefore attempted to establish baseline information on the status of the 40 species of threatened vertebrates in Vietnam that could potentially occur in the Reserve. (2) The disappearance of large vertebrates from the Reserve reflects a general loss of biodiversity but the status of other, more common, species in Vietnam's Red Data Book was unknown. We therefore attempted to establish the mean abundance of these vertebrates over the last 3 decades to ascertain any population trends. (3) Environmental characteristics differ between the seven communes in the Reserve and we therefore studied population trends of the surveyed vertebrates by commune. Given the administrative organisation of the Reserve it is important to identify problems within each commune in the interests of informing the appropriate authorities about any conservation actions required.

\section{Study area}

The 19,254 ha Ngoc Son Ngo Luong was declared a Nature Reserve in 2004 (Fig. 1). It lies on the boundary of two regional tectonic zones of the $\mathrm{Ma}$ and $\mathrm{Da}$ rivers. The limestone topography is characterised by sheer rock outcrops and highly dissected karst terrain. Altitudes in the Reserve are 200-1,400 m (Do et al., 2008). Vegetation cover comprises two main forest types: tropical seasonal evergreen forests, and subtropical seasonal evergreen forests with three subtypes (evergreen forests on limestone, evergreen forests on shale and basalt rocks, and forest plantations; Do et al., 2008). These mountains are partially protected to the south-east by the Cuc Phuong National Park (the first National Park declared in Vietnam) and to the north-west by Pu Luong Nature Reserve. Although these two protected areas have been studied (Averyanov et al., 2003; Dang, 2004; Nadler et al., 2004; Nadler \& Wicker, 2009), little is known about the biodiversity of Ngoc Son Ngo Luong Nature Reserve (BirdLife International \& FIPI, 2001). The local population was moved out of Cuc Phuong when it was declared a National Park in 1966, with concomitant socio-economic effects (Rugendyke \& Nguyen, 2005). Ngoc Son Ngo Luong Nature Reserve is, however, still home to c. 14,000 people $(>2,500$ families) in 51 villages across seven communes (Nguyen \& Munz, 2010; Table 1). Most of these people belong to the Muong ethnic minority and $>30 \%$ live below the poverty line (Do \& Bui, 2008). This, together with management problems, is leading to the illegal extraction of timber, poaching and illegal trafficking of protected species.

\section{Methods}

We prepared a book with photographs of the 40 species of threatened terrestrial vertebrates in the Red Data Book of Vietnam (Ministry of Science and Technology of Vietnam, 2007; Supplementary Table S1) that were recorded in the preliminary inventory of the Reserve's potential fauna (Dat et al., 2008). These photographs were shown to local 
TABle 1 The seven communes in the Ngoc Son Ngo Luong Nature Reserve (Fig. 1), with number of villages, number of households in 2009, number of hunters (identified by facilitators in their own communes) and the number of hunters interviewed.

\begin{tabular}{lcllll}
\hline Commune & $\begin{array}{l}\text { No. of } \\
\text { villages }\end{array}$ & $\begin{array}{l}\text { No. of } \\
\text { households } \\
\text { in 2009 }\end{array}$ & $\begin{array}{l}\text { No. of } \\
\text { hunters }\end{array}$ & $\begin{array}{l}\text { No. of interviewees } \\
\text { (included in } \\
\text { analysis) }\end{array}$ & $\begin{array}{l}\text { Conservation } \\
\text { problems }\end{array}$ \\
\hline Bac Son & 5 & 292 & 8 & 8 & $1,2,3,4$ \\
Nam Son & 7 & 321 & 10 & 6 & $1,2,3,4$ \\
Ngo Luong & 6 & 283 & 10 & 9 & $1,2,3$ \\
Ngoc Son & 8 & 486 & 13 & 8 & $1,2,3$ \\
Tu Do & 10 & 514 & 39 & 9 & $1,2,3$ \\
Ngoc Lau & 13 & 533 & 45 & $9(7)$ & $1,2,3$ \\
Tan My & 2 & 86 & 18 & $9(5)$ & $1,2,3,4$ \\
\hline
\end{tabular}

${ }^{*}$, growing human population; 2, illegal hunting (poaching and subsistence purposes); 3 , deforestation; 4, mining

hunters, asking them to confirm or rule out the presence of these species in the area and, if present or formerly present, to rate their abundance on a scale of $0-3$ (o, extinct; 1 , rare; 2 , common; 3 , very abundant). To assess the quality of their responses the photographs also included the Cat Ba langur Trachypithecus poliocephalus (a species occurring only on Cat Ba Island, north-east Vietnam), and the male and female of the northern white-cheeked crested gibbon Nomascus leucogenys were presented as different species; the male is black with white cheeks whereas the female is uniformly light brown.

The questionnaire-based surveys were conducted in 2009 with the help of a local facilitator from each commune who had been working with the project Ngoc Son Ngo Luong since 2007. The facilitators attended an induction regarding the objectives, working plan and technical details of the survey. They visited the hunters in their communes to explain, in Muong, the objective of the questionnaire and to invite them to participate. Use of local facilitators avoided any cross-cultural interactions that could affect the data gathered. A total of 58 hunters agreed to answer the questionnaire (Table 1). Each facilitator explained and then completed the questionnaire in the hunter's home. This method is appropriate when independent information is required and the type of information sought is known beforehand (Huntington, 2000). Each hunter was asked to rate the abundance of each species in the area in the mid 1970 s (before Doi Moi) and in 2009. Information from six hunters from the communes of Tan My and Ngoc Lau who were too young to have memories of the mid 1970s was excluded from the study.

Except for these all the hunters identified the species in their Muong name and were able to identify the male and female northern white-cheeked crested gibbon as the same species; they also ruled out the presence in the area of the Cat Ba langur and Javan chevrotain Tragulus javanicus, a species whose existence had been mooted in the preliminary inventory (Dat et al., 2008). Following the administration of the questionnaires the hunters were invited to participate in a workshop, with the technical assistance of the facilitator of each commune, forest rangers and local authorities. After feedback of the results the participants built up amongst them a picture of the environmental evolution of the commune, paying particular attention to the threats to the 40 species (such as overhunting, deforestation and mining; Table 1). Thus an overview of the Nature Reserve was pieced together from the joint input of the communes.

Differences between the mid 1970 s and 2009 in the number and mean abundance of species, as determined from information provided by the hunters and communes, were analysed with a repeated measures ANOVA, incorporating the commune as a classification factor. The mean abundance of each species in each commune was calculated as the mean of the abundance (on a $0-3$ scale, see above) estimated by each hunter. A comparison was also made of any change in those vertebrate groups with a sufficient number of species (mammals and reptiles) for analysis, and for primates and carnivores. Low sample size precluded separate analysis of the data for birds (three species) and amphibians (one species).

For each commune we calculated the mean of the mean abundance index estimated by each hunter for 1975 and 2009. The total number of species in each period was calculated by accumulating the species observed by all hunters. These data were used to analyse any changes in vertebrates between communes. Any potential effect of mining on the number of species that have gone extinct in each commune was examined by a comparison between communes with and without mining activities (Table 1), using an ANCOVA in which the loss of species per commune between 1975 and 2009 was the dependent variable, the presence/absence of mining was the classification factor and species richness in 1975 was the covariate.

\section{Results}

According to the hunters 39 of the 40 species have existed or still exist in the Nature Reserve. The only species that has 
never existed there, at least in the previous 60 years, is the Javan chevrotain. Of the others five are now extinct (Delacour's langur, northern white-cheeked crested gibbon, dhole, oriental small-clawed otter Aonyx cinereus and Indochinese tiger) and there is no explicit evidence for the continued presence of six species, although they could persist in remote areas of the Reserve (Phayre's leaf-monkey Trachypithecus phayrei ssp. crepuscula, sun bear Helarctos malayanus, binturong Arctictis binturong, fishing cat Prionailurus viverrinus, leopard Panthera pardus and wreathed hornbill Aceros undulatus). According to the hunters some of the other 28 species have been reduced to such low numbers (Supplementary Table $\mathrm{S}_{1}$ ) that they are now on the verge of extinction (e.g. Chinese pangolin Manis pentadactyla).

Information from the hunters indicates a decline in the number and abundance of vertebrates (Fig. 2a,b); this trend is common to all communes (Table 2). There are large apparent differences between the two time periods and some communes have lost more than others (see communex period interaction in Table 3). A similar pattern was observed in the comparison of mammals and reptiles, with a significant interaction between taxon and period. There were greater losses of mammals than of reptiles (Table 3, Fig. 2c). The abundance of primates and carnivores also fell between the two periods, with a greater drop in primates (Table 3, Fig. 2d).

Some of the most species-rich communes in 1975, such as Tu Do and Ngo Luong, also appeared to have the most species in 2009 but suffered a higher number of local extinctions (Table 2). Mining had no statistically significant effect on these extinctions, although there were greater losses in areas with mining $\left(F_{1,4}=4.72, \mathrm{P}=0.096\right)$.

\section{Discussion}

\section{Information on the species present in the Reserve}

In recent years local ecological knowledge has been incorporated into decision-making in the management of protected areas and species (Usher, 2000;
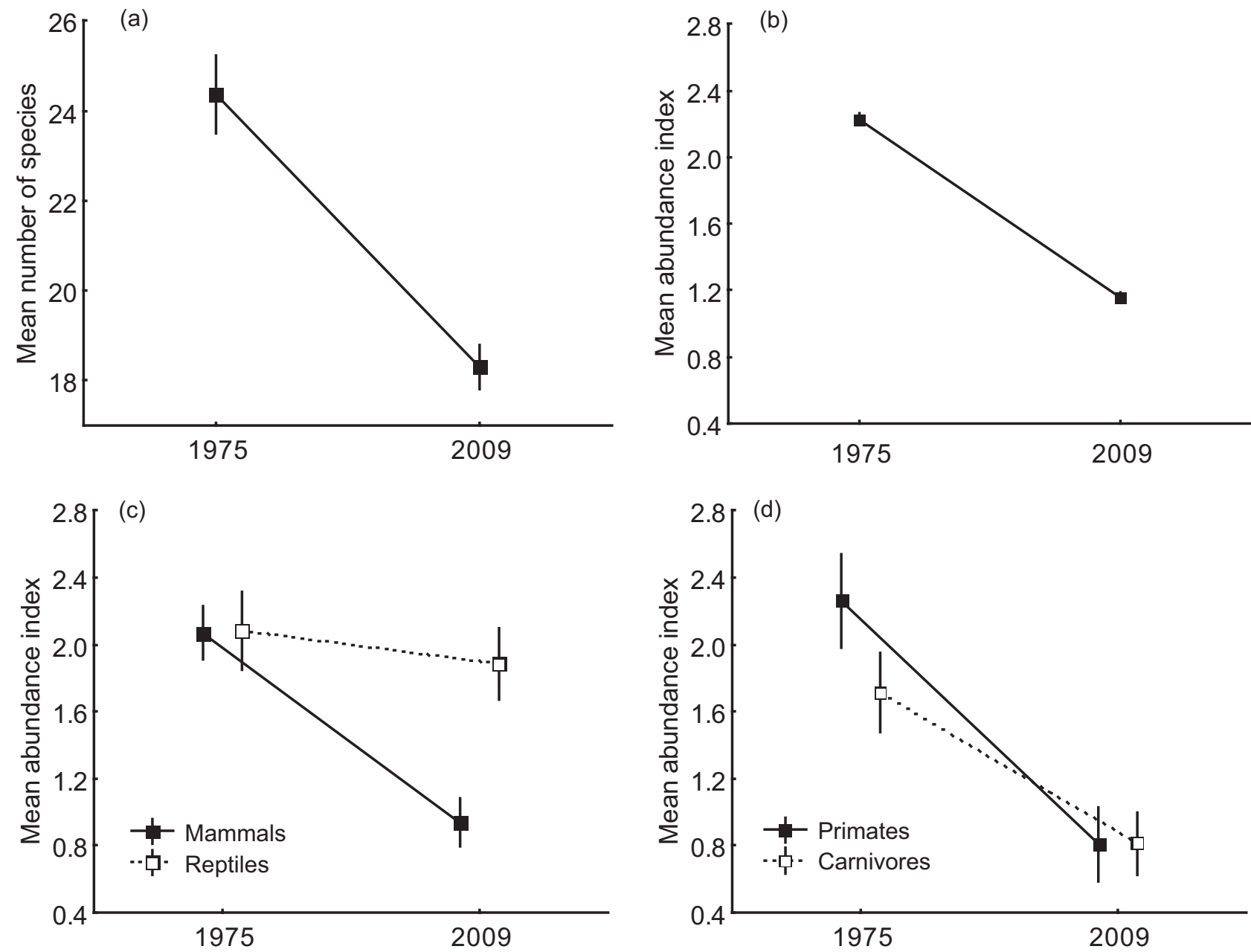

FIG. 2 Mean ( \pm SE) (a) number of species, abundance index of (b) all species (c) mammals and reptiles only, and (d) primates and carnivores only, in 1975 and 2009, for all seven communes combined. 
TABLE 2 Mean abundance index (see text for further details) and number of species, in 1975 and 2009, calculated from information provided by individual hunters interviewed in the seven communes (Table 1) in Ngoc Son Ngo Luong Nature Reserve (Fig. 1).

\begin{tabular}{llllr}
\hline & \multicolumn{2}{l}{ Mean abundance \pm SE } & & \multicolumn{2}{l}{ No. of species \pm SE } \\
\cline { 2 - 3 } Commune & 1975 & 2009 & 1975 & 2009 \\
\hline Bac Son & $2.14 \pm 0.06$ & $1.02 \pm 0.89$ & $19.20 \pm 1.92$ & $14.42 \pm 1.03$ \\
Nam Son & $2.21 \pm 0.07$ & $0.99 \pm 0.85$ & $20.50 \pm 3.03$ & $17.66 \pm 1.11$ \\
Ngo Luong & $2.26 \pm 0.06$ & $1.13 \pm 1.02$ & $28.00 \pm 1.43$ & $20.88 \pm 0.90$ \\
Ngoc Son & $2.29 \pm 0.06$ & $1.54 \pm 1.41$ & $24.80 \pm 1.92$ & $20.37 \pm 0.96$ \\
Tu Do & $2.30 \pm 0.06$ & $1.22 \pm 1.11$ & $29.00 \pm 1.75$ & $19.66 \pm 0.90$ \\
Ngoc Lau & $2.42 \pm 0.07$ & $1.08 \pm 0.95$ & $20.14 \pm 1.62$ & $15 \pm 1.03$ \\
Tan My & $1.79 \pm 0.08$ & $0.96 \pm 0.80$ & $24.40 \pm 1.92$ & $18.60 \pm 1.21$ \\
\hline
\end{tabular}

TABLE 3 Result of the repeated measures ANOVA used to analyse changes in the number and abundance of species by time period (1975 vs 2009) and commune (and their interaction), and by particular taxa (mammals vs reptiles and primates vs carnivores) and time period (and their interaction).

\begin{tabular}{lrr}
\hline & df & \multicolumn{1}{c}{$F$} \\
\hline No. of species & 6 & $4.96^{* * *}$ \\
Commune & 1 & $100.45^{* * *}$ \\
Period & 6 & $3.29^{* *}$ \\
Commune $\times$ Period & 31 & \\
Error & & 1.76 \\
Abundance & 6 & $335.14^{* * *}$ \\
Commune & 1 & $2.36^{*}$ \\
Period & 6 & \\
Commune $\times$ Period & 209 & $14.48^{* * *}$ \\
Error & & $159.05^{* * *}$ \\
Mammals vs reptiles & 1 & $78.79^{* * *}$ \\
Taxon & 1 & \\
Period & 1 & $3.42^{*}$ \\
Taxon $\times$ Period & 188 & $240.55^{* * *}$ \\
Error & & $13.36^{* * *}$ \\
Primates vs carnivores & 1 & \\
Taxon & 1 & \\
Period & 1 & \\
Taxon $\times$ Period & 99 & \\
Error & & \\
\hline
\end{tabular}

${ }^{*} \mathrm{P}<0.05 ;{ }^{* * \mathrm{P}}<0.01 ;{ }^{* *} \mathrm{P}<0.001$

Steinzmetz et al., 2006; Dollo et al., 2010). In the case of Ngoc Son Ngo Luong Nature Reserve the information furnished by local hunters from the seven communes indicates the major changes that have occurred in vertebrate composition and abundance since 1975. Large mammals have been the most affected, as one would expect given the extensive loss of habitat and endemic species in South-east Asia (Hoekstra et al., 2005; Brooks et al., 2006). Information provided by hunters on the loss and decline of some vertebrate species concords with reports from neighbouring areas. For example, according to the hunters the northern white-cheeked crested gibbon disappeared from the Reserve in the mid 1980s but was already rare by the 1970s (the last was hunted in 1986 in one of the most heavily forested area of the Reserve). Nadler et al. (2004) estimated that this gibbon disappeared from the adjacent $\mathrm{Pu}$ Luong Nature Reserve in the mid 1980s. The most striking example is the disappearance of Delacour's langur in the central portion of its reduced range (Nadler et al., 2007). The previously scarce information on this endemic species in Ngoc Son Ngo Luong indicated the existence of two small groups of no more than 10-11 individuals in 2000-2005 (FIPI, 2005); the last three individuals in the Reserve may have been hunted in 2004 (Dat et al., 2008). Hunters have not seen this species in the subsequent 7 years. Nadler et al. (2004) and the interviewed hunters also indicated that the same area was the last known location of Phayre's leaf-monkey. The site indicated by our survey respondents is that identified by genetic analysis of the species' faecal remains (Nadler et al., 2007). There was a general consensus about the critical state of the Chinese pangolin, coinciding with studies in the adjacent Cuc Phuong National Park (Newton et al., 2008). The hunters have not seen recent signs of the wreathed hornbill in the Reserve (Cano \& Pham, 2010). It seem to be a rare bird in the region and there is only one known record in Cuc Phuong National Park (Nadler \& Wicker, 2009), a site that attracts many birdwatchers.

In addition to corroboration of the hunters' knowledge with information from other studies, the hunters' local ecological knowledge was also borne out by other indirect evidence. For example, the gibbon's cries, which are very far-reaching, ceased to be heard by local people in the area in the same years in which the hunters claim that the northern white-cheeked crested gibbon disappeared. Similarly, attacks on cattle by dholes also ceased, according to local people and forest rangers, at the time when hunters indicated that they had disappeared, and similarly for fatal attacks by tigers on people. Conversely, other indirect evidence confirmed that some species still occur. For example, maize-crop damage by bears was verified during the harvest season from direct observations and tracks. 


\section{Changes in abundance and species composition}

The hunters indicated there has been a decline in the number of vertebrate species and their abundance from 1975 to 2009 , with a decline from reasonably abundant (a mean abundance index of 2.2) to rare $(<1.2)$ throughout the Reserve (Fig. 2b). This indicates conservation problems for this Reserve and adjacent protected areas. The situation is particularly critical for mammals, some of which have already disappeared from the area. The declines can be attributed to illegal hunting and deforestation. Illegal hunting (poaching and subsistence hunting) affects mammals more than reptiles as mammals are more keenly sought by the local hunters. Large and medium-sized mammals are also the most sensitive to deforestation in this region (Newton et al., 2008).

\section{Spatial breakdown of conservation problems}

Although loss of species and reduction in numbers have occurred throughout the Reserve, this has not been uniform. Not only has there been a general reduction in the abundance of vertebrates throughout the Reserve but there has also been a narrowing of the differences in abundance between communes. In 1975, for example, the estimated mean abundance indices for Ngo Lau and $\mathrm{Tu}$ Do communes were $>2.2$ but by 2009 they were $<1.25$ (Table 2). This might have been because hunters that formerly hunted near their villages were forced by the progressive impoverishment of species to hunt in the formerly species-rich communes. In addition most local extinctions were experienced by the communes that had the most species 3 decades ago. In addition to the pressures resulting from the increase in the human population, deforestation and poaching, which are common to all communes, mining has further exacerbated the situation in certain communes. The current situation in Ngoc Son Ngo Luong Nature Reserve is similar to that in other protected sites in South-east Asia, where mammal populations (especially those of ungulates, carnivores and primates) are declining (Steinzmetz et al., 2006; Lau et al., 2010; Starr et al., 2011) because of the pressures from deforestation, and commercial and subsistence hunting.

\section{Conclusions}

In summary, the disappearance or decline of vertebrate species in Ngoc Son Ngo Luong Nature Reserve and nearby areas, as indicated by the information furnished by the local population and from preliminary reports, can be attributed to a variety of causes. The impacts of these could be minimized by proper management and effective operational plans compatible with the inhabitants' needs (such as the sustainable management of hunting). This study was used as a decision-making tool to set up conservation priorities and budget allocations for research on some animal groups in the Operational and Conservation Plan for the Ngoc Son Ngo Luong Nature Reserve, Hoa Binh Province, 2010-2014 (Le Duc \& Cano, 2010). The planning procedure followed a participatory process directed by the Forest Protection Department of Hoa Binh and included information and suggestions provided by the local hunters. This plan has been in place since 2011. Following this, continued research on the conservation status of mammals has been carried out (Willcox \& Tanh Hao, 2011). Our study has also been used as a source of information on the national conservation status of some of the studied species (Rawson et al., 2011).

\section{Acknowledgements}

We thank Mr Bui Van Tuong, Director of the Forest Protection Department (FPD) of Hoa Binh province and Mr Bui Binh Yen, Director of Ngoc Son Ngo Luong Nature Reserve, for their support, and Mr Quang Pham Thien (FPD-Hoa Binh) for his contribution to the field work. The Foundation for the Social Promotion of Culture, Vietnam team, was fully involved in the field work. Tilo Nadler provided useful comments on the data. Dr J.A. Díaz helped with the initial analysis. We thank two anonymous referees for their valuable comments and constructive suggestions, and Dave Langlois and Sarah Young for translation. This study, as well as the Ngoc Son Ngo Luong Project reports, come under Convention 06-Co1-009 of the Spanish Agency of International Cooperation and Development (Agencia Española de Cooperación Internacional y Desarrollo: Planificación y desarrollo del ecoturismo en el entorno de la reserva natural de Ngoc Hoa Binh, proporcionando pequeñas infraestructuras, formación y materiales).

\section{References}

Averyanov, L.V., Nguyen, T.H., Phan, K.L., Do, T.D. \& Regalado, J.C. (2003) Preliminary Botanical Survey of Primary Vegetation in Pu Luong Nature Reserve, Thanh Hoa Province. Unpublished Report. Pu Luong-Cuc Phuong Conservation Limestone Landscape Conservation Project, Fauna \& Flora International-Vietnam Programme, Hanoi, Vietnam.

Baltzer, M.C., NGuyen, T.D. \& Shore, R.G. (2001) Towards a Vision for Biodiversity Conservation in the Forests of the Lower Mekong Ecoregion Complex: Technical Annex. WWF Indochina/ WWF US, Hanoi, Vietnam, and Washington, DC, USA.

Berkes, F. (2008) Sacred Ecology: Traditional Ecological Knowledge and Resource Management, 2nd edition. Taylor and Francis, Philadelphia, USA.

Birdife International \& FiPI (Forest Inventory and Planning Institute) (2001) Sourcebook of Existing and Proposed Protected Areas in Vietnam. BirdLife International \& Forest Inventory and Planning Institute, Hanoi, Vietnam. 
Brooks, T.M., Mittermeier, R.A., da Fonseca, G.A.B., Gerlach, J., Hoffmann, M., Lamoreux, J.F. et al. (2006) Global biodiversity conservation priorities. Science, 313, 58-61.

Bui Binh, Y., Pham, Q.T., Nguyen, B.D. \& Cano, L.S. (2008) ShortTerm Action Plan for the Ngoc Son Ngo Luong Nature Reserve. Unpublished Report, Ngoc Son Ngo Luong Nature Reserve Project. FPSC/FPD Hoa Binh/AECID, Hoa Binh, Vietnam.

Cano, L.S. \& Pham, Q.T. (2010) An Approach to Key Extinguished, Threatened and Endangered Vertebrate Species in Ngoc Son Luong Nature Reserve of Hoa Binh Province. Unpublished Report No. 7 , Ngoc Son Ngo Luong Nature Reserve Project. FPSC/FPD Hoa Binh/ AECID, Hoa Binh, Vietnam.

Castella, J.-C., Boissau, S., Nguyen, H.T. \& Novosad, P. (2006) Impact of forestland allocation on land use in a mountainous province of Vietnam. Land Use Policy, 23, 147-160.

D ANG, N.C. (2004) A Mammal Survey and Conservation Assessment of Selected Sites at Pu Luong Nature Reserve, Thanh Hoa Province. Unpublished Report. Pu Luong-Cuc Phuong Limestone Landscape Conservation Project, Fauna \& Flora International-Vietnam Programme and the Forest Protection Department, Hanoi, Vietnam.

DAt, L.T., HuY, D.Q., DUC, L.T., VINH, L.Q. \& HaO, L.V. (2008) Survey on Vertebrate Fauna of Ngoc Son-Ngo Luong Nature Reserve. Unpublished Report No. 2, Ngoc Son Ngo Luong Nature Reserve Project. FPSC/FPD Hoa Binh/AECID/FFI, Hanoi, Vietnam.

Do, A.T. \& BuI, M.H. (2008) Survey Report on Land Use and Forestry Use. Unpublished Report No. 3, Ngoc Son Ngo Luong Nature Reserve Project. FPSC/FPD Hoa Binh/AECID/FFI, Hanoi, Vietnam.

Do, A.T., Phung, V.P., NGuyen, V.H. \& NGuyen, D.M. (2008) Survey Report on Forest Type Survey. Unpublished Report No. 1, Ngoc Son Ngo Luong Nature Reserve Project. FPSC/FPD Hoa Binh/ AECID/FFI, Hanoi, Vietnam.

Dollo, M., Gopi, G.V., Teegalapalli, K. \& Mazumdar, K. (2010) Conservation of the orange-bellied Himalayan squirrel Dremomys lokriah using a traditional knowledge system: a case study from Arunachal Pradesh, India. Oryx, 44, 573-576.

FFi (Fauna \& Flora International) (2005) Pu Luong-Cuc Phuong Limestone Landscape Project. Project Reports \& Publications 2002-2005. CDROM. FFI, Hanoi, Vietnam.

FIPI (Forest Inventory and Planning Institute) (2005) Feasibility Study to Establish the Ngoc Son Ngo Luong Nature Reserve. Unpublished Report. Ministry of Agriculture and Rural Development, Hanoi, Vietnam. [In Vietnamese]

Hoekstra, J.M., Boucher, T.M., Ricketts, T.H. \& Roberts, C. (2005) Confronting a biome crisis: global disparities of habitat loss and protection. Ecology Letters, 8, 23-29.

Huntington, H.P. (2000) Using traditional ecological knowledge in science: methods and applications. Ecological Applications, 10, $1270-1274$

LaU, M.W.-N., Fellowes, J.R. \& Chan, B.P.L. (2010) Carnivores (Mammalia: Carnivora) in south China: a status review with notes on the commercial trade. Mammal Review, 40, 247-292.

Le Duc, Minh \& CAno, L.S. (2010) Operational Management and Conservation Plan for Ngoc Son Ngo Luong Nature Reserve, Hoa Binh Province, 2010-2014. Technical Report No. 5. Ngoc Son Ngo Luong Nature Reserve Project and Forest Protection Department, Hoa Binh, Vietnam.

Ministry of Science and Technology of Vietnam (2007) Vietnam's Red Data Book, Vol. 1: Animals. Natural Sciences and Technology Publishing House, Hanoi, Vietnam. [In Vietnamese]
Nadler, T., Le, T.D. \& Luong, V.H. (2004) A Primate Field Survey at $P u$ Luong Nature Reserve with the Emphasis on Delacour's Langur (Trachypithecus delacouri). Unpublished Report. Fauna \& Flora International Vietnam Conservation Support Programme and the Forest Protection Department, Hanoi, in association with the Frankfort Zoological Society-Vietnam Primate Conservation Programme.

Nadler, T., Vu, N.T. \& Streicher, U. (2007) Conservation status of Vietnamese primates. Vietnamese Journal of Primatology, 1, 7-26.

Nadler, T. \& Wicker, F. (2009) Birds of Cuc Phuong National ParkA Checklist. Frankfurt Zoological Society, Hanoi, Vietnam.

Newton, P., Nguyen, V.T., Roberton, S. \& Bell, D. (2008) Pangolins in peril: using local hunters' knowledge to conserve elusive species in Vietnam. Endangered Species Research, 6, 41-53.

Nguyen, D.H.C. \& Munz, A. (2010) Tourism Development and Management Framework: Ngoc Son-Ngo Luong Nature Reserve. Unpublished Technical Report No. 4.2 Ngoc Son Ngo Luong Nature Reserve Project. FPSC/FPD Hoa Binh/AECID/Tourism Resources Consultants, Hanoi, Vietnam.

Rasalato, E., Maginnity, V. \& Brunnschweiler, J.M. (2010) Using local ecological knowledge to identify shark river habitats in Fiji (South Pacific). Environmental Conservation, 37, 90-97.

Rawson, B.M., Insua-Cao, P., Nguyen Manh Ha, Van Ngoc Thinh, Hoang Minh Duc, Mahood, S. et al. (2011) The Conservation Status of Gibbons in Vietnam. Fauna \& Flora International/Conservation International, Hanoi, Vietnam.

Rugendye, B. \& Nguyen, T.S. (2005) Conservation costs: nature-based tourism as development at Cuc Phuong National Park, Vietnam. Asia Pacific Viewpoint, 46, 185-200.

Starr, C., Nekaris, K.A.I., Streicher, U. \& Leung, L.K.-P. (2011) Field surveys of the Vulnerable pygmy slow loris Nycticebus pygmaeus using local knowledge in Mondulkiri Province, Cambodia. Oryx, 45, 135-142.

Steinzmetz, R., Chutipong, W. \& Seuaturien, N. (2006) Collaborating to conserve large mammals in South-east Asia. Conservation Biology, 20, 1391-1401.

Usher, P.J. (2000) Traditional ecological knowledge in environmental assessment and management. Arctic, 53, 183-193.

Wilhere, G.F. (2002) Adaptive management in habitat conservation plans. Conservation Biology, 16, 20-29.

Willcox, D. \& Do, T.H. (2011) The Status of Small Carnivores and Pangolins in Ngoc Son-Ngo Luong Nature Reserve, Hoa Binh Province, Vietnam. Unpublished Report No. 10, Ngoc Son Ngo Luong Nature Reserve Project. The Carnivore and Pangolin Conservation Program/FPSC/FPD Hoa Binh/AECID, Hoa Binh, Vietnam.

\section{Biographical sketches}

LUis SANTiago CANo works on the management of international cooperation projects and conservation strategies for local communities and threatened species. He is interested in resolving conflicts between wildlife and socio-economic interests through scientific research and application of technology, social awareness and capacity building to improve the livelihood of local people in sensitive areas. José LUIs TELLERÍA is interested in vertebrate biology and conservation, and has conducted studies on the distribution of Iberian vertebrates, bird migration and the ecology of vertebrate communities in fragmented landscapes. $\mathrm{He}$ is interested in international cooperation projects related to wildlife conservation. 